\title{
DESEMPENHO DA COLHEDORA DE MILHO PENHA CLM-350 - PARTE I - SISTEMA ESPIGADOR *
}

\author{
J.A. Furlani Jr. ** \\ J.B. Guimarães Jr. ** \\ L.A. Balastreire ****
}

\section{RESUMO}

Com o propósito de avaliar a colhedora Penha CLM-350, visando fornecer subsídios aos projetos e usuários, rcalizou-se o presente trabalho, onde foi estudada a eficácia do sistema espigador, determinando-se a porcentagem de milho colhido para os diversos tratamentos estudados.

Definiu-se um parâmetro adimensional $U$, que é a relação entre a valocidade periférica dos roletes e a velocidade de deslocamento da colhedora. Procurou-se relacionar os diversos tratamentos $U$, com os valores percentuais de grãos de milho colhidos e perdidos no solo.

Os resultados foram estudados através da análise de variância, empregando-se o teste $\mathrm{F}$, aos níveis de $1 \%$ e $5 \%$ de probabilidade e o teste Tukey para a comparação estatística entre as médias.

A análise estatística permitiu concluir-se, que em relação a porcentagem de milho colhido os tratamentos não tiveram efeitos significativos, mantendo-se a eficácia acima de $84,42 \%$ nas condições do ensaio. Na faixa operacional estudada, determinada como praticável nas condições de campo, cobrindo as especificaçôes de campo, os valones de $\mathrm{U}$ foram limitados. Esta característica é inerente às relações de transmissão adotadas pelo projeto da colhedora e sugerem a adaptação de um órgão, que possibilite a variação da relação de transmissão da tomada de potência para os roletes espigadores, que proporcione u'a maior gama de variação para $U$ e o estabelecimento de uma relação matemática com a eficácia.

* Trabalho apresentado no V Congresso Nacional de Engenharia Agrícola, de 16 a 19 de julho de 1975, em Lavras - MG. Trabalho entregue para publicação em 31-12-1977.

* Dept. ${ }^{\circ}$ de Eng. Rural da Faculdade de Ciencias Agronômicas, Campus de Botucatu - UNESP.

*** Departamento de Engenharia Rural - ESALQ-USI*. 


\section{INTRODUÇÃO}

Embora a primeira colhedora de milho tenha surgido no século XIX, ainda hoje não tem seu emprego difundido em nosso país. Vários fatores influiram para que isso não tivesse ocorrido. Inicialmente, só a uma década a mecanização agrícola tem atingido altos níveis de emprego e sua tendência é aumentar esses níveis nos anos vindouros. Por outro lado, não existiam máquinas de colheita mecânica de milho e as importadas, pouco difundiāas e de custo inicial elevado, nâo tinham condições de competir com a mão-de-obra, relativamente de baixo preço e a pouca. remuneração çue esse produto alcançava no mercado consumidor.

Com $\mathrm{c}$ advento de uma colhedora de milho de produção nacional, com o enorme aumento da mecanização agrícola, pela escassez de mãode-obra, pelas necesisdades crescentes do produto e pela boa remuneração do mercado é justo e certo, que o uso de colhedoras mecânicas de milho deve aumentar gradualmente.

No entanto, a colheita mecânica do milho é influenciada por diversos fatores que se não conhecidos e controlados podem comprometer o custo da produção e mesmo o produto. No tocante a planta em si, são necessários hibridos de alta produtividade, cuja planta permaneça erecta até seu completo amadurecimento.

Quanto às colhedoras de um modo geral, durante a colheita produzem uma perda de milho no campo em graus e condições variáveis. Existem perdas que podem ser consideradas anteriores a passagem da colhedora, influenciadas principalmente pela época de colheita, representadas pelas espigas de milho e plantas caidas, além dos danos causados por agentes ambientais e organismos nocivos. Durante a operação de colheita mecânica, ocorrem perdas pelo tombamento de plantas, provocado pelo avanço da máquina; pelo debulhamento indesejável nos roletes espigadores; pelo sistema de limpeza, que elimina grãos juntamente com sabugos, palhas e outras impurezas; pelo mau debulhamento e pelos danos mecânicos sofridos pelo milho, no sistema debuthador, que não só depreciam o produto, como facilitam a ação de organismos nocivos durante o armazenamento.

Evidentemente a grandeza dessas perdas, devidas a colhedora, se nà ' podem, ser totalmente eliminadas, podem ser minimizadas. Nesse sentia, grande número de pesquisadores tem trabalhado, procurando projet::r novos componentes, aperfeiçoar os existentes e obter informações e dados, que permitam, colheitas mecânicas com menores perdas.

Considerando a importância do milho e as necessidades de sua produção, procurou-se neste trabalho estudar o desempenho de uma colhedora-debulhadora com base na eficácia do sistema espigador determinando-se as perdas de milho no chão e milho colhido pela máquina em relaçĩo a velocidade de trabalho, e velocidade periférica dos roletes. 
Os ensaios foram conduzidos durante dois anos em condições usuais de culturi no campo, instalados nas Fazendas Experimentais desta Fac ... dairde sencio que no primeiro ano foram feitos os ensaios preliminares que não fazem parte deste relato, mas que subsidiaram o presente trabalho.

\section{REVISÃO DA LITERATURA}

Compilando-se a literatura encontra-se indicaçōes sobre as melhores épocas e técnicas de plantio, melhores épocas e técnicas de colheita e desempenhos comparativos de diversas máquinas utilzadas principalmente nos Estados Unidos e Europa, dentre os quais pode-se destacar:

PICKARD e BATEMAN (1959) considerando a importância da planta de milho, para o bom desempenho de uma colhedora mecânica, estudaram esse tipo de colheita em culturas de milho anão. Concluiram que esse híbrido apresenta alta resistência a queda de plantas e espigas e que as culturas apresentam um bom padrão de plantas, o que concorre para reduzir as perdas da colheita, particularmente nas tardias. Acrescentem que tornam-se necessárias modificações para prevenir o excessivo debulhamento das espigas mais baixas.

BURROUGH e HARBAGE (1953) realizaram ensaios de campo, com uma colhedora-debulhadora, objetivando avaliar o efeito da época da colheita na eficiência da operação e determinar as características varietais que acarretassem maiores efeitos na umidade debulhadora Concluiram que para teores de umidade de 24,9\% no grão de milho, as perdas, em porcentagem da produção total, tiveram a seguinte distribuição: 2,6\% de espigas perdidas no solo em pré-colheita, 2,6\% de grãos debulhados nos rolos espigadores, $8,9 \%$ de espigas perdidas pela colhedora.

BARKSTROM (1955) estudando diversos tipos de rolos espigadores em relação a teores de umidade do grão, variando entre 9 a $12 \%$, concluiu que as perdas por debulhamento nos rolos espigadores, eram de $1,95 \%$ em média.

RICHEY et al (1956) relataram o projeto de uma nova espigadora, onde os rolos espigadores são dispostos de forma convergente e sobrepostos. Segundo os autores esse tipo perde em milho debulhado pelos rolos espigadores 0,5 a 0,75 das perdas da espigadora convencional. Essa vantagem aumenta, quando o milho torna-se mais sêco e as perdas de milho debulhado no sistema aumentam.

JOHNSON et al (1963) apresentam um trabalho em que se objetiva determinar o efeito do método de colheita e do teor de umidade sa perda total, ao mesmo tempo em que procura caracterizar a qualidade do grão de milho nos vários teores de umidade. Entre as conclusões que chegaram, observou-se que não existe relação aparente entre a umidade do grão e as perdas nos rolos espigadores. 
BYG e HALL (1968) conduziram experimentos com combinadas na colheita de milho, durante trsê anos, com os objetivos de determinar as perdas totais das máquinas na colheita, perdas nos componentes das máquinas, práticas operacionais e certas especificações concernentes a cultura do milho. Verificaram que a velocidade de trabalho para as combinadas não se apresentam tão constante como era esperado. Evidenciou que a velocidade diminui quando o número de ruas a ser colhida pela máquina aumenta.

Poucas são as referências a ensaios realizados em nossas condições, quantificando os parâmetros envolvidcs na mesma.

São mais usuais descrições de máquinas colhedoras e algumas normas operacionais.

SAAD (1961) estudou uma espigadora de milho, em condições de campo, com os objetivos de determinar a melhor época para a colheita e uma série de fatores, que poderiam ou não influir na colheita mecanizada, tais como: profundidade de semeadura, variedade de milho híbrido e diâmetros das plantas, espiga e sabugo. Pelos dados obtidos concluiu que não houve influência de profundidade dos tipos de milho utilizado, da altura da espiga e das dimensões da espiga e sabugo na colheita.

\section{MATERIAIS E MÉTODOS}

\section{a. Cultura do milho}

As plantas de milho utilizadas no presente trabalho foram cultivadas na Fazenda Experimental São Manoel. O solo onde foi instalada a cultura é uma unidade Mangueira - Seca, transição entre solos com B latossólico e B textural, ao nível de reconhecimento seria provavelmente na unidade Latosol Vermelho Escuro - fase arenosa.

O plantio da cultura foi realizado de 20 a 25 de novembro, utilizando-se o híbrido HMD 7974 da Secretaria da Agricultura. A semeadura foi mecânica, com semeadora-adubadora de 2 linhas, tendo um espaçamento de 1 metro entre linhas e com posterior desbaste manual, para que a cultura permanecesse em média com 5 plantas por metro linear.

A colheita mecânica da cultura foi realizada no dia 12 de maio de 1973, tendo as plantas de milho 175 dias aproximadamente.

b. Colhedora mecânica de milho

A máquina utilizada na colheita mecânica do milho e objeto deste estudo, foi a de marca Penha, modelo CLM-350. Sua colocação é lateral 
ao trator, sendo semi-montada. Colhe uma linha de plantas por vez, sendo acionada pela TDP *

Os órgãos funcionais da colhedora estão dispostos em linha sob a armação. Todos eles são acionados por 2 eixos paralelos; um superior, no qual são montados a rosca coletora, o debulhador e o rotor do aspirador; e um inferior onde encontra-se os roletes, a rosca condutora horizontal e os elevadores de palhetas. Todos esses órgãos são blinơados externamente, figuras 1 e 2 .

Na parte frontal da máquina aparecem os bicos coletores, constituídos por chapas metálicas formando um semi-cone. Tem por função encaminhar as plantas de milho, no sentido vertical, para o interior da colhedora, mais diretamente para os roletes (Figura $1, n .^{\mathbf{0}} 1$ ). Os roletes em número de dois, paraleios entre si, são constituídos por um tubo cilíndrico central, sobre o qual são soldados, no seu sentido longitudinal, lâminas. Os roletes girando em sentido contrário, laminam a planta de milho de baixo para cima e retiram as espigas existentes, pois não há possibilidade destas passarem pela luz existente entre os roletes. Sob os roletes existem quatro facas, cuja função é mante-los livres de "embuchamento", provocado por ervas daninhas que tenham se estabelecido na cultura (Fig. 2, n. ${ }^{\circ} 13$ ).

Sobre os roletes está colocada a rosca coletora que nada mais é do que um transportador helicoidal. Sua função é auxiliar a apreensão cios colmos pelos roletes e encaminhar as espigas colhidas para o sistema debulhador (Fig. 2, n. ${ }^{\circ} 1$ ).

\section{c. Tacômetro}

Para medição da rotação dos eixos paralelos da colhedora, quando em operação, foi utilizado um tacômetro, marca JAQUET, modelo 620 , portátil, com escalas de leitura de 30 a $12.000 \mathrm{rpm}$. - Foram usadas as escalas de 300 a $1200 \mathrm{rpm}$, com sensibilidade de $10 \mathrm{rpm}$ e a de 1000 a $4000 \mathrm{rpm}$, com sensibilidade de $50 \mathrm{rpm}$.

Foram determinados 5 tratamentos, que levaram em conta as marchas da caixa de transmissão e as rotações do motor de um Trator Massey-Ferguson modelo $65 \mathrm{X}$. Consequentemente, variou-se a velocidade de deslocamento da colhedora, bem como as rotações de seus sistemas afins. Os tratamentos foram denominados de A,B,C,D e E. Nos tratamentos $A, B, C, e D$, utilizou-se a terceira marcha reduzida do trator, com o motor trabalhando nos regimes de $1400,1600,1800$ e $200 \mathrm{rpm}$ respectivamente. No tratamento $\mathrm{E}$ utilizou-se a segunda marcha simples do trator, com o regime de $1400 \mathrm{rpm}$ do motor. Esses parâmetros dos tratamentos produziriam velocidades de deslocamento e rotações dos sistemas da colhedora, cobrindo a faixa de melhor utilização, recomendada pelo fabricante.

* TD P - Tomada de potência de acordo com a ABNT. 

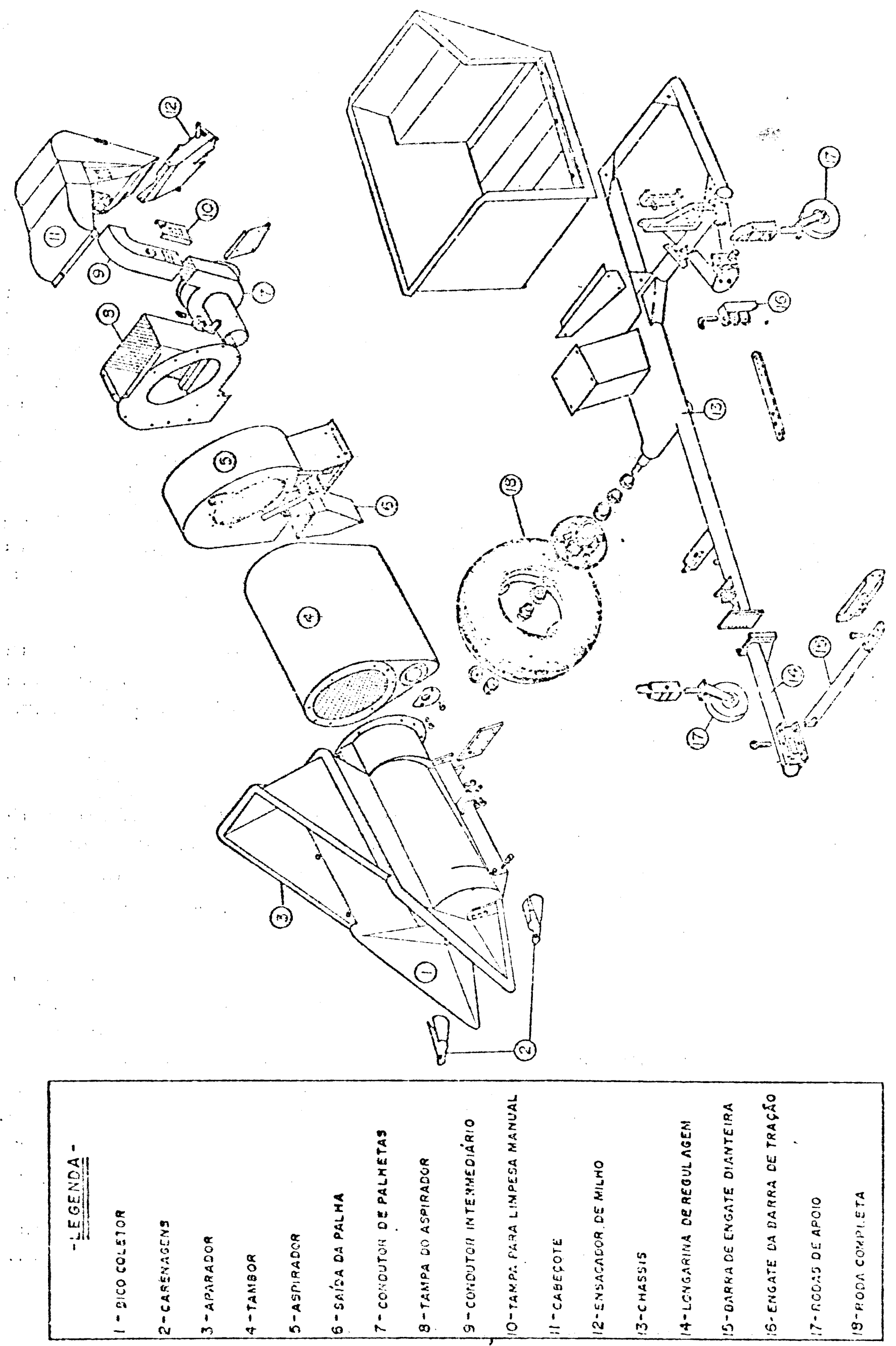


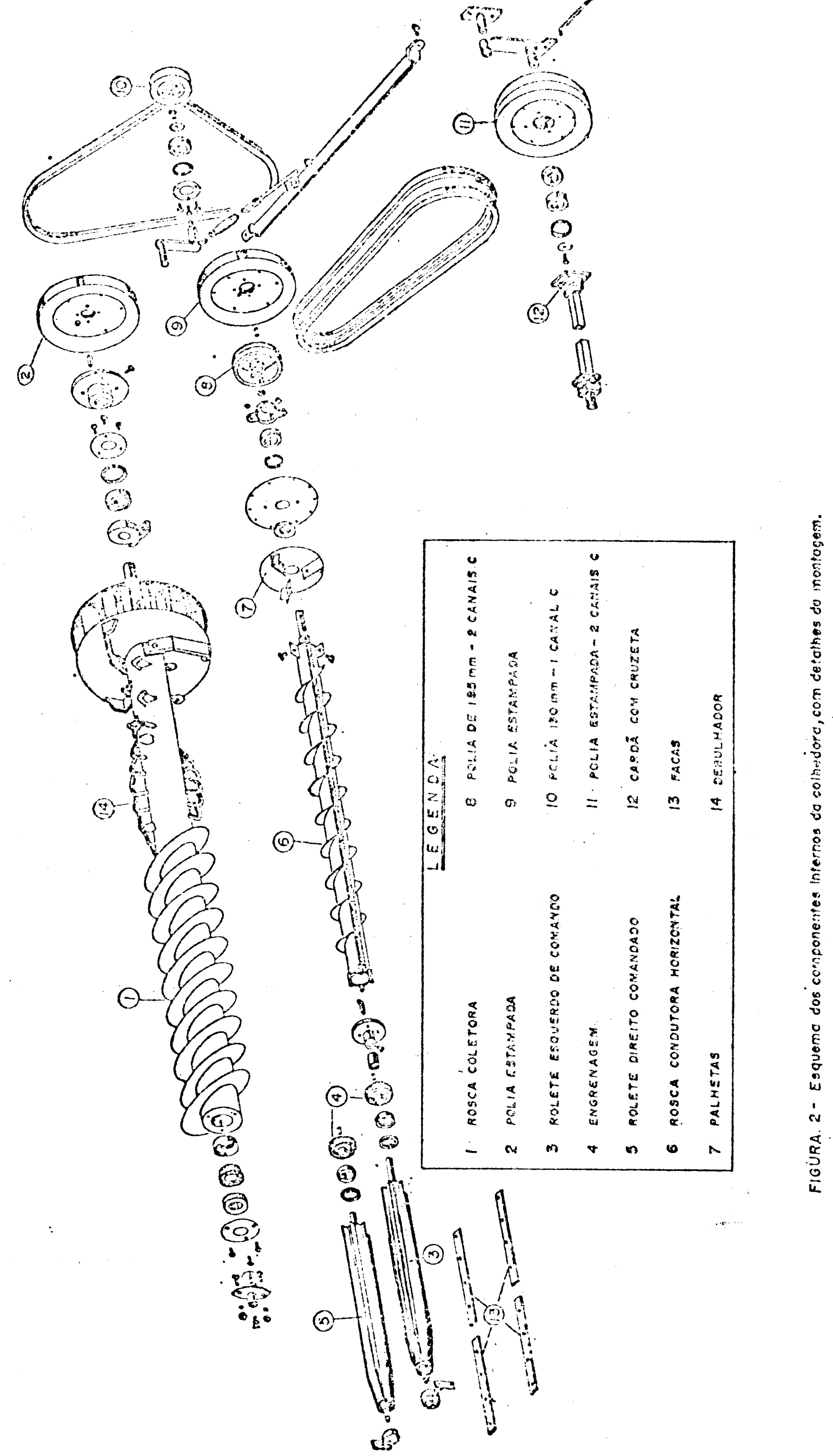


No presente ensaio foram avaliados os seguintes parâmetros ,arbitrados como relevantes para avaliar o comportamento da máquina:

- Perdas em grãos de milho no campo em pré-colheita: São as espigas caidas das plantas ou piantas caidas ou muito inclinadas fora da ação da máquina. Essa avaliação é necessária para o cálculo da produção total da parcela e sistemas de recolhimento. Para esse fim, procedia-se o recolhimento manual do milho caido no chão ou fora de alcance da máquina. O milho recolhido seria posteriormente pesado, obtendo-se o valor porcentual em grãos de milho, perdidos em pré-colheita em relação à produção total da parcela.

- Perdas no campo durante a colheita: após a execução da colheita mecânica de cada parcela, as plantas derubadas pelo impacto da colhedora e os grãos debulhados pelos roletes eram recolhidos manualmente para futuras pesagens e obtenção do valor percentual em grãos de milho perdidos pela colhedora no solo. Esse valor é calculado, tomando o milho possível de ser colhido mecanicamente como $100 \%$. Essas perdas são provocadas pela ação dos roletes e da velocidade de deslocamento da colhedora.

Se considerar-se uma alta velocidade periférica dos roletes utilizada concomitantemente com baixa velocidade de deslocamento da máquina, deverá ocorrer uma ação mecânica muito enérgica de laminação do colmo e maiores danos as espigas, podendo ainda provocar pelo impacto, perdas de espigas e grãos inconvenientemente debulhados nos roletes. Por outro lado, para uma baixa velocidade periférica dos roletes, associada com alta velocidade de deslocamento da colhedora, exigirá pela rapidez com que os colmos atingem os roletes, uma capacidade de apreensão, que os mesmos não possuem, resultando no tombamento da planta e consequente perda de milho.

Neste trabalho procurou-se relacionar esses dois parâmetros da colhedora com os valores percentuais de grãos de milho colhidos e perdidos no solo. Para tal fim utilizou-se uma relação $U$, onde:

$$
U=\frac{\text { velocidade periférica dos roletes }}{\text { velocidade de deslocamento da colhedora }}
$$

A velocidade de deslocamento da colhedora foi determinada, cronometrando-se o tempo gasto para a colheita completa de cada parcela.

A rotação do motor do trator, para os diversos tratamentos, era mantida constante pelo uso do tacômetro do mesmo. As rotações médias dos eixos da colhedora foram determinadas com o uso do tacômetro, em cada tratamento, durante a colheita da respectiva parcela. 
Para que somente as plantas pertencentes a parcela fossem verdadeiramente colhidas, 5 metros lineares de plantas eram eliminadas manualmente, antes e após a linha da parcela. repetições.

O delineamento foi em blocos ao acaso com 5 tratamentos e 6

As parcelas de cada tratamento consistiam de 10 metros lineares de linha de plantio de milho.

Os resultados obtidos foram estudados através da análise de variância, empregando-se o Teste $\mathrm{F}$ aos níveis de $1 \%$ e $5 \%$ de probabilidade. O Teste Tukey aos níveis de $1 \%$ e $5 \%$ de probabilidade foi utilizado para comparação estatística entre as médias dos tratamentos.

Os testes $\mathrm{F}$ e de Tukey foram realizados com os dados transformados em arco seno $\vee \%$.

\section{RESULTADOS E DISCUSSÃO}

Com o propósito de facilitar a análise dos resultados, são apresentadas as médias das 6 repetições de cada tratamento.

Quadro 1 - Perda percentual de grãos de milho em pré-colheita

\begin{tabular}{cc}
\hline Tratamentos & $\begin{array}{c}\text { Grãos de milho } \\
\text { perdidos }\end{array}$ \\
\hline A & 12,91 \\
$\mathrm{~B}$ & 14,75 \\
$\mathrm{C}$ & 8,00 \\
$\mathrm{D}$ & 17,11 \\
$\mathrm{E}$ & 13,12 \\
\hline MEDIA GERAL & 13,17 \\
\hline
\end{tabular}

A análise de variância dos valores obtidos para as perdas em précolheita são apresentados no Quadro 3. Essa análise permite admitir, que as perdas percentuais de milho em pré-colheita, nas diferentes parcelas amostradas, não diferiram estatisticamente entre si. Em razão disso, pode-se estabelecer que nas condições do ensaio essas perdas apresentaram um valor de $13,17 \%$ da produção total. 
Quadro 2 - Resultados da eficácia do sistema espigador para os diversos tratamenios

\begin{tabular}{|c|c|c|c|c|c|c|}
\hline $\begin{array}{l}\text { Tra- } \\
\text { ta } \\
\text { men- } \\
\text { to }\end{array}$ & $\begin{array}{c}\text { Velocidade } \\
\text { da colhedora } \\
\mathrm{m} / \mathrm{s}\end{array}$ & $\begin{array}{l}\text { Rotação dos } \\
\text { roletes } \\
\text { rpm }\end{array}$ & $\begin{array}{c}\text { Velocidade } \\
\text { dos roletes } \\
\text { (periférica) } \\
\mathrm{m} / \mathrm{s}\end{array}$ & $\begin{array}{c}\text { Relação } \\
\text { U }\end{array}$ & $\begin{array}{c}\text { Grãos de } \\
\text { milho colhi- } \\
\text { dos } \\
\%\end{array}$ & $\begin{array}{c}\text { Grãos de } \\
\text { milho per- } \\
\text { didos } \\
\%\end{array}$ \\
\hline $\mathrm{A}$ & 1,11 & 837,5 & 6,16 & 5,60 & 93,45 & 6,55 \\
\hline B & 1,34 & 967,5 & 7,15 & 5,34 & 95,75 & 4,25 \\
\hline $\mathrm{C}$ & 1,45 & 1082,5 & 8,00 & 5,50 & 93.30 & 6,70 \\
\hline D & 1,58 & 1241,7 & 9,18 & 5,76 & 84,42 & 15,58 \\
\hline $\mathrm{E}$ & 2,46 & 820,0 & 6,06 & 2,46 & 88,93 & 11,07 \\
\hline
\end{tabular}

Quadro 3 - Análise da variância dos dados referentes as perdas em pré-colheita

\begin{tabular}{lrrrr}
\hline $\begin{array}{l}\text { Causas de } \\
\text { variação }\end{array}$ & Gr L & $\begin{array}{c}\text { Soma dos } \\
\text { quadrados }\end{array}$ & $\begin{array}{c}\text { Quadrados } \\
\text { médios }\end{array}$ & F. \\
\hline \hline $\begin{array}{l}\text { Blocos } \\
\text { Tratamento }\end{array}$ & 5 & 359,30 & 71,86 & 1,61 N.S. \\
Resíduo & 4 & 254,30 & 63,58 & 1,43 N.S. \\
\hline Total & 20 & 890,06 & 44,50 & \\
\hline
\end{tabular}

$\mathrm{CV}=33,15 \%$

Sendo $U$ um valor decorrente da relação entre a velocidade periférica dos roletes e a velocidade de deslocamento da máquina, valores estes que são afetados diretamente pela rotação do motor e a relação de transmissão do trator, mas que são também afetados por fatores não controláveis em condições de campo, inicialmente procedeu-se uma análise para se estabelecer, se os valores de $U$ determinados diferiam entre si, em função dos tratamentos definidos.

No Quadro 4, apresenta-se a análise de variância dos valores obtidos para $U$ e no Quadro 5, a análise da variância para a porcentagem de milho colhido. 
Quadro 4 - Análise da variância dos dados referentes aos valores de U.

\begin{tabular}{lrrrr}
\hline $\begin{array}{l}\text { Causas de } \\
\text { variação }\end{array}$ & G L & $\begin{array}{c}\text { Soma dos } \\
\text { quadrados }\end{array}$ & $\begin{array}{c}\text { Quadrados } \\
\text { médios }\end{array}$ & F \\
\hline \hline $\begin{array}{l}\text { Blocos } \\
\text { Tratamento }\end{array}$ & 5 & 0,2160 & 0,0432 & 1,5495 N.S. \\
Resíduo & 20 & 46,3285 & $\begin{array}{r}11,5821 \\
6,0279\end{array}$ & $415,4028 * *$ \\
\hline Total & 29 & 0,5576 & & \\
\hline $\mathrm{CV}=3,39 \%$ & 47,1021 &
\end{tabular}

Nos testes das médias foram encontradas diferenças altamente significativas. De tal forma que o tratamento $D$ apresentou a maior média. Contudo apenas diferiu estatisticamente dos tratamentos $B$ e $E$. Este último tratamento apresentou a menor média, a qual diferiu estatisticamente dos demais tratamentos.

Quadro 5 - Análise da variância para a porcentagem de milho colhido

\begin{tabular}{lrrrr}
\hline $\begin{array}{l}\text { Causas de } \\
\text { variação }\end{array}$ & G L & $\begin{array}{l}\text { Soma dos } \\
\text { quadrados }\end{array}$ & $\begin{array}{l}\text { Quadrados } \\
\text { médios }\end{array}$ & F \\
\hline Blocos & 5 & 592,2631 & 118,4526 & 1,7068 N.S. \\
Tratamento & 4 & 324,7533 & $\begin{array}{l}81,1883 \\
69,3988\end{array}$ & 1,1699 N.S. \\
Resíduo & 20 & $1.387,9764$ & & \\
\hline Total & 29 & $2.304,9928$ & \\
\hline
\end{tabular}

$\mathrm{CV}=11,17 \%$

Pela análise pode-se inferir que em relação a porcentagem de milho colhido, os tratamentos não tiveram efeito significativo.

Esse parâmetro que em última análise expressa a eficácia do sistema espigador da colhedora, manteve-se em níveis superiores a $84,42 \%$ nas condições do ensaio.

\section{CONCLUSÕES}

Do exposto, pode-se concluir que quando se utilizou a terceira marcha reduzida do trator, com as rotações do motor de 1400, 1600 e 1800 
rpm os valores obtidos para $U$ não diferiram significativamente entre si ao nivel de 5\% de probabilidade. Por outro lado, nessa mesma relação de transmissão, com as rotações de 1600 e $2000 \mathrm{rpm}$, os valores obtidos para $U$ apresentaram diferenças significativas entre si ao nír əl de $1 \%$ de probabilidade. - Quando se utilizou a segunda marcha simples com a rotação do motor de $1400 \mathrm{rpm}$, obteve-se um valor de $U$ que diferiu significativamente dos demais, ao nível de $1 \%$ de probabilidade. Isso leva a concluir que, na faixa operacional estudada, determinada como praticável em condições de campo, cobrindo as especificações do fabricante, os valores de $U$ foram limitados. Das análises da relação $U$ e da porcentagem de milho colhido, emiora houvessem diferenças significativas entre alguns dos valores de $U$ empregados, não acarretaram diferenças significativas nos valores da eficácia do sistema espigador da máquina que manteve-se a níveis superiores a 84,42\%. Oscilou entre $84,42 \%$ a $95,75 \%$ nas condições do ensaio. Os valores obtidos para $U$, sugerem a adoção de um órgão que possibilite a variação da relação de transmissão da TDP para os roletes espigadores, que proporcione uma maior gama de variação para $U$ e uma relação com a eficácia para ser estabelecida.

\section{SUMMARY}

\section{PERFORMANCE OF THE PENHA CLM-350 CORN COMBINE - PART I EAR PICKING SYSTEM}

This work was designed with the aim of evaluating the performance of the Penha CLM-350 corn combine, to furnish data to designers and users. The efficiency of the ear picking system was studied, and the percentage of the harvested corn was determined for the various treatments considered.

A dimensionless $U$ parameter was defined as the ratio between the peripheral speed of the snapping rolls and the speed of the harvester.

The $\mathrm{U}$ terms were related to the percentages of corn harvested and corn lost on the ground.

The analysis of variance with the $\mathrm{F}$ test at $1 \%$ and $5 \%$ probability levels was utilized to analyse the data, and Tukey's test was utilized for comparison between means.

The statistical analysis showed that the treatment were not significant for the percentage of harvested corn, the efficiency maintained above $84,42 \%$ for the test conditions. For the conditions tested the values were limited by mechanical characteristics of the combine, particularly the transmission ratio. This suggests the design of a mechanism, which should provide the possibility of changing the transmission ratio from the tractor power take-off to the snapping rolls. This would provide a wider range of variation for $U$ and could provide a mathematical relationship with efficiency. 


\section{I.ITERATURA CITADA}

FARKSTROM, R., Attachments for combining corn. Agricultural Engineering. St. Joseph, Michigan, U.S.A. 36(12): 799-800. 1955.

BURROUGH, D.E. and R.P. Harbage. Performance of a corn pickersheller. Agricultural Engineering. St. Joseph, Michigan, U.S.A. 34(1):21-22, 1953.

BYG, D.M. and G.E. Hall, Corn losses and damage in field shelling of corn. Transactions of the A.S.A.E. St. Joseph, Michigan, U.S.A. 11(2): 164-166. 1968.

JOHNSON, W.H., B.J. Lamp., J.E. Henry and G.E. Hall, Corn harvesting performance at various dates. Transaction of the A.S.A.E. St. Joseph, Michigan, U.S.A. 6(3):268-272, 1963.

PICKARD, G.E., H.P. Bateman, Experiments in harvesting dwarf corn. Agricultural Engineering St. Joseph, Michigan, U.S.A. 40(12): 732-735, 1959.

R!CHEY, C.B., J.F. O'Donnell, J.T. Ashton and R.J. Groves, Corn picher features new principles. Agricultural Engineering. St. Joseph, Michigan, U.S.A. 37(2): 93-97, 1956.

SAAD, O. Estudo da espigadora na colheita mecânica do milho. Tese apresentada ao concurso de docência livre da $15 .^{\text {a }}$ Cadeira, Mecânica e Máquinas Agrícolas da Escola Superió de Agricultura "Luiz de Queiroz" da Universidade de São Paulo. Piracicaba, Estado de São Paulo, 1961, 56 páginas. 
